\title{
Slippery when sticky: Lubricating properties of thin films of Taxus baccata aril mucilage
}

Røn, Troels; Sankaranarayanan, Rishikesan; Chronakis, loannis S.; Lee, Seunghwan

Published in:

Biointerphases

Link to article, DOI:

$10.1116 / 1.4942208$

Publication date:

2016

Document Version

Publisher's PDF, also known as Version of record

Link back to DTU Orbit

Citation (APA):

Røn, T., Sankaranarayanan, R., Chronakis, I. S., \& Lee, S. (2016). Slippery when sticky: Lubricating properties of thin films of Taxus baccata aril mucilage. Biointerphases, 11(1), [011010 ]. https://doi.org/10.1116/1.4942208

\section{General rights}

Copyright and moral rights for the publications made accessible in the public portal are retained by the authors and/or other copyright owners and it is a condition of accessing publications that users recognise and abide by the legal requirements associated with these rights.

- Users may download and print one copy of any publication from the public portal for the purpose of private study or research.

- You may not further distribute the material or use it for any profit-making activity or commercial gain

- You may freely distribute the URL identifying the publication in the public portal 


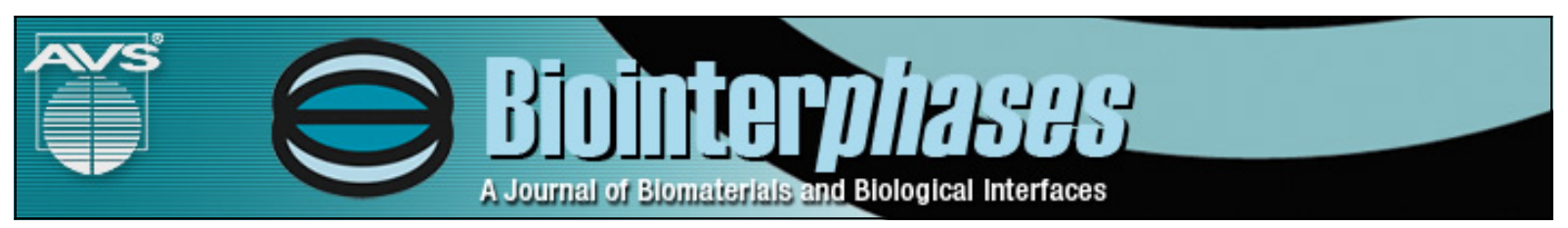

\section{Slippery when sticky: Lubricating properties of thin films of Taxus baccata aril mucilage}

Troels Røn, Sankaranarayanan Rishikesan, loannis S. Chronakis, and Seunghwan Lee

Citation: Biointerphases 11, 011010 (2016); doi: 10.1116/1.4942208

View online: http://dx.doi.org/10.1116/1.4942208

View Table of Contents: http://scitation.aip.org/content/avs/journal/bip/11/1?ver=pdfcov

Published by the AVS: Science \& Technology of Materials, Interfaces, and Processing

\section{Articles you may be interested in}

Thin film lubrication of hexadecane confined by iron and iron oxide surfaces: A crucial role of surface structure

J. Chem. Phys. 143, 164702 (2015); 10.1063/1.4933203

Molecular dynamics simulations of lubricant spreading on lubricant-patterned substrates

J. Appl. Phys. 100, 084902 (2006); 10.1063/1.2358083

Acoustic measurement of lubricant-film thickness distribution in ball bearings

J. Acoust. Soc. Am. 119, 863 (2006); 10.1121/1.2146109

Stability analysis of ultrathin lubricant films via surface energy measurements and molecular dynamics simulations

J. Appl. Phys. 97, 10P302 (2005); 10.1063/1.1849073

The stability of evaporating thin liquid films in the presence of surfactant. I. Lubrication approximation and linear analysis

Phys. Fluids 10, 131 (1998); 10.1063/1.869555 


\title{
Slippery when sticky: Lubricating properties of thin films of Taxus baccata aril mucilage
}

\author{
Troels Røn and Sankaranarayanan Rishikesan \\ Department of Mechanical Engineering, Technical University of Denmark, DK-2800 Kgs. Lyngby, Denmark \\ loannis S. Chronakis \\ Nano-BioScience Research Group, DTU-Food, Technical University of Denmark, DK-2800 Kgs. Lyngby, \\ Denmark \\ Seunghwan Lee ${ }^{\text {a) }}$ \\ Department of Mechanical Engineering, Technical University of Denmark, DK-2800 Kgs. Lyngby, Denmark
}

(Received 10 December 2015; accepted 5 February 2016; published 22 February 2016)

\begin{abstract}
Mucilage is hydrogel produced from succulent plants and microorganisms displaying unique adhesiveness and slipperiness simultaneously. The objective of this study is to establish an understanding on the lubricating mechanisms of the mucilage from Taxus baccata aril as thin, viscous lubricant films. Oscillation and flow rheological studies revealed that $T$. baccata mucilage is shear-thinning, thixotropic, and weak hydrogel that is highly stretchable under shear stress due to its high density physical crosslinking characteristics. In addition, $T$. baccata mucilage showed a distinct Weissenberg effect, i.e., increasing normal force with increasing shear rate, and thus it contributes to deplete the lubricant from tribological interfaces. Lubrication studies with a number of tribopairs with varying mechanical properties and surface wettability have shown that the lubricity of $T$. baccata mucilage is most effectively manifested at soft, hydrophilic, and rolling tribological contacts. Based on tenacious spreading on highly wetting surfaces, slip plane can be formed within mucilage hydrogel network even when the lubricating films cannot completely separate the opposing surfaces. Moreover, highly stretchable characteristics of mucilage under high shear enhance smooth shearing of two opposing surfaces as lubricating film. (C) 2016 American Vacuum Society. [http://dx.doi.org/10.1116/1.4942208]
\end{abstract}

\section{INTRODUCTION}

Mucilage is naturally occurring hydrogel or exopolysaccharide produced by succulent plants and microorganisms. ${ }^{1,2}$ Biological functions of mucilage in plants include storage of water, assistance in seed germination, membrane thickening, etc. ${ }^{1,2}$ More specialized role is observed in carnivorous plants, for instance, sundew (Drosera sp.), where mucilage exudes are used to attract and capture prey via its dew-like appearance which are highly sticky in nature. ${ }^{3,4}$ Engineering these adhesive properties of mucilage is beneficial largely in its pharmaceutical applications, such as binding agent in tablets, ${ }^{5}$ gelling agent, ${ }^{6}$ demulcent, on mucosa membrane, ${ }^{7}$ and industrial applications as in glues for bonding paper items. ${ }^{8}$

Recently, lubricity of mucilage, a seemingly opposite characteristic to its adhesive properties, has drawn an increasing interest. For example, tribological studies of the mucilage from aloe, ${ }^{9}$ quince, ${ }^{10}$ and Brasenia schreberi ${ }^{11,12}$ have shown effective boundary lubrication of engineering materials, such as tungsten carbide/diamondlike carbon (WC/DLC), polyethylene/stainless steel, and self-mated quartz glass pairs. Interest in the tribological properties of mucilage is partly initiated from recent social demands of development and/or fabrication of ecofriendly lubricants. ${ }^{13,14}$ More importantly, the lubrication mechanism of mucilage is very unique and different from conventional

\footnotetext{
${ }^{a)}$ Electronic mail: seele@mek.dtu.dk
}

lubricants in many senses; while the viscosities of mucilage ${ }^{15,16}$ are similar to conventional lubricant base stock, ${ }^{17}$ boundary lubricating performance of mucilage is exceptionally effective between two moving surfaces. ${ }^{9-12}$ It was observed that lubricating efficacy appears to be closely related to their wetting properties on the tribopair surfaces. For example, $B$. schreberi mucilage showed a coefficient of friction $0.004-0.006$ between two quartz glass surfaces, and its tenacious bonding to the glass surface was proposed as a reason for extremely low interfacial friction forces. ${ }^{12}$

In the present study, we are interested to understand the lubricating properties of mucilage from arils of Taxus baccata (also known as "yew," Fig. 1). ${ }^{18-23}$

$T$. baccata is a conifer native to and abundant in Europe. Apart from botanical subjects, scientific interest on $T$. baccata tree has predominantly focused on the toxicity of its seeds, leaves, and barks. ${ }^{22,23}$ Aril, the berry flesh surrounding the seeds [Fig. 1(a)], are the only part known to be nontoxic, and is thought to serve as "lure" to birds and animals for seed dispersal. ${ }^{22,23}$ Mucilage is dispersed within the flesh of aril and can easily be obtained by squeezing the berries. Even though no particular tribological function is identified from $T$. baccata mucilage in biological system, as with other mucilage, its slipperiness can be readily felt by rubbing it between fingers and systematic rheological/tribological studies may extend our understanding on the lubricating properties of mucilage in general. Two particularly interesting characteristics that we have observed from $T$. baccata aril 

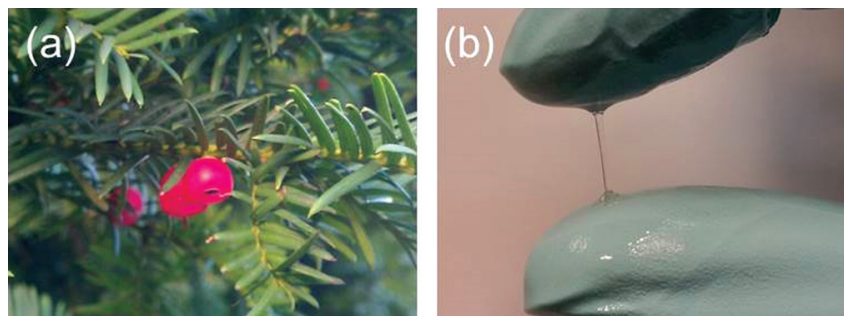

FIG. 1. (a) T. baccata (English yew) showing red berries containing mucilage. (b) Mucilage squeezed from the aril of the berry showing extensional properties between human fingers with nitrile gloves.

mucilage as lubricating fluids are: First, T. baccata mucilage displays not only slipperiness but also reveal a strong adhesion between two surfaces [Fig. 1(b)] and its magnitude varies significantly from one surface to another. Second, T. baccata mucilage displays a very distinct Weissenberg effect in its rheological properties; when a spinning rod is inserted into the fluid showing Weissenberg effect, it is drawn toward the rod and rises up instead of being thrown outwards. ${ }^{24}$ At a tribological interface, for example, in a pin-on-disk configuration, this effect is manifested as depletion of lubricant fluid toward center of the rotating disk with increasing shear force, and yet, the lubricants can be possibly recovered at even higher shear. An opposing force to the depletion is the tendency of mucilage to retain at the tribological interface arising from the wettability onto tribopair surfaces. Thus, it is important to employ several tribopairs with different surface wettability in order to investigate the relationship between the adhesive properties and lubricity of $T$. baccata mucilage.

\section{EXPERIMENT}

\section{A. Mucilage sample and other reference lubricants}

Mucilage samples were prepared by squeezing the berries picked from European T. baccata trees in the area ca. $15 \mathrm{~km}$ north of Copenhagen, Denmark. MilliQ water (resistivity $\geq 18 \mathrm{M} \Omega \mathrm{cm}$, referred as "water" throughout the study) was employed as a reference lubricant. Anhydrous glycerol ( $\geq 99.5 \%)$ from Sigma-Aldrich was employed for a control experiment.

\section{B. Water content and SDS-PAGE}

The water content of yew mucilage was characterized by comparing the pristine and dried mass of mucilage. The protein and carbohydrate contents were analyzed on 4\%-12\% sodium dodecyl sulfate-polyacrylamide gel electrophoresis (SDS-PAGE) by dissolving $10 \mu \mathrm{l}$ of the mucilage with equal volume of phosphate buffered saline. Two equally prepared gels were stained, respectively, to detect the presence of proteins by Simply Blue ${ }^{\mathrm{TM}}$ Safe Stain (Life Technologies Corporation $^{\circledR}, 2012$.) and carbohydrates by periodic acidSchiff (PAS).

\section{Shear and oscillation rheometry}

Rheological properties of T. baccata mucilage were characterized with a controlled stress HAAKE $^{\text {TM }}$ MARS $^{\text {TM }}$ rheometer (Thermo Scientific, Inc., Germany) using a $6 \mathrm{~cm}$ cone-plate geometry $\left(\mathrm{C} 60 / 1^{\circ}\right)$. Mucilage was loaded on to the rheometer sample plate at $25^{\circ} \mathrm{C}$, and the frequency sweep in the linear viscoelastic region $(0.01-100 \mathrm{rad} / \mathrm{s})$ and stress sweep (at a frequency of $1 \mathrm{~Hz} \approx 6.28 \mathrm{rad} / \mathrm{s}$ ) were carried out keeping the temperature constant. Flow measurements were performed right after frequency sweeps at the same temperature.

\section{Tribopairs}

Four different categories of tribopairs were employed (ball-disk): (1) high density polyethylene-high density polyethylene (HDPE-HDPE) to represent hard-hydrophobic interface, (2) poly(dimethylsiloxane)-poly(dimethylsiloxane) (PDMS-PDMS) to represent soft-hydrophobic interface, (3) steel-PDMS and steel-oxidized PDMS (steel-oxPDMS) to represent soft-hydrophilic interfaces (the former is "half-hydrophilic"), and (4) steel-glass to represent hard-hydrophilic interface. HDPE disks were prepared by cutting the commercially available rods (Rias A/S, Roskilde, Denmark) and polishing (silicon carbide paper, Grit 1000). Commercially available HDPE balls $\left[\frac{3}{4}\right.$ in. $(19.05 \mathrm{~mm})$ in diameter] were used as received (Precision Plastic Ball Company, Franklin Park, IL). Commercially available bearing steel balls (AISI E 52100) and glass disks were also employed (PCS Instruments, London, UK). Steel balls and glass disks were always hydrophilized by air plasma treatment with a plasma cleaner/sterilizer (Harrick Plasma, model PDC-002, New York, NY) for $2 \mathrm{~min}$ at $30 \mathrm{~W}$ prior to tribological experiments. PDMS balls and disks were fabricated from a two-component kit (SYLGARD ${ }^{\circledR} 184$, Dow Corning, Midland, MI) consisting of base PDMS and cross-linker according to a standard procedure. ${ }^{25}$ For PDMS disk, the mixture fluid of based PDMS and crosslinker was poured on top of a polytetrafluoroethylene (PTFE) disk in a plastic mold with nearly the same diameter and cured overnight at $70{ }^{\circ} \mathrm{C}$. The thickness of PDMS disk on top of the PTFE was $2 \mathrm{~mm}$. PDMS balls with $\frac{3}{4}$ in. $(19.05 \mathrm{~mm})$ diameter were cast in a home-machined aluminum mold. PDMS balls and disks were also hydrophilized in the same way with steel balls and glass disks to prepare hydrophilic PDMS surfaces (oxPDMS). Water contact angles of untreated and plasmatreated substrates are provided in Table I.

Surface roughness of the disks and balls was characterized by acquiring root-mean-square roughness $\left(R_{\mathrm{q}}\right)$ from topographic images of $100 \times 100 \mu \mathrm{m}$ area with a tappingmode AFM (Bruker AFM model Dimension ${ }^{\circledR}$ Edge $^{\mathrm{TM}}$ ). Three different spots were characterized for statistical evaluation. The full lists of the surface roughness of the tribopairs are shown in Table I. NANOSCOPE 8.02 software was used for AFM imaging, with NANOSCOPE ANALYSIS software (ver. 1.40) for the calculation of surface roughness. Due to the changes in surface roughness from lapping (plastic deformation) of asperities on HDPE tribopairs during tribological experiments, roughness of HDPE ball and disk was characterized on the sliding tracks after tribological tests. 
TABLE I. List of materials for tribopairs, including mechanical properties, surface roughness, and wettability by water and mucilage.

\begin{tabular}{|c|c|c|c|c|c|c|c|c|}
\hline \multirow[b]{2}{*}{ Substrate } & \multirow[b]{2}{*}{$\begin{array}{l}\text { Young's modulus } \\
\text { (MPa) }\end{array}$} & \multirow[b]{2}{*}{$\begin{array}{c}\text { Contact pressure } \\
(\mathrm{MPa})^{\mathrm{c}}\end{array}$} & \multirow[b]{2}{*}{$\begin{array}{l}\text { Poisson's } \\
\text { ratio }\end{array}$} & \multicolumn{2}{|c|}{ Roughness, $R_{\mathrm{q}}(\mathrm{nm})$} & \multirow{2}{*}{$\begin{array}{c}\text { Static contact } \\
\text { angle }\left(^{\circ}\right) \\
\text { by water }\end{array}$} & \multirow{2}{*}{$\begin{array}{c}\text { Static contact } \\
\text { angle }\left(^{\circ}\right) \\
\text { by mucilage }\end{array}$} & \multirow{2}{*}{$\begin{array}{c}\text { Static contac } \\
\text { angle }\left(^{\circ}\right) \\
\text { by glycerol }\end{array}$} \\
\hline & & & & Disk & Ball & & & \\
\hline PDMS & $\begin{array}{c}2.0(\text { Ref. 26) (6.9) } \\
\quad(\text { Ref. 27) }\end{array}$ & 0.24 & 0.5 & $1.6 \pm 0.3$ & $121.4 \pm 36.4$ & $105.6 \pm 2.2$ & $106.1 \pm 0.6$ & $111.0 \pm 0.5$ \\
\hline HDPE & 1080 (Ref. 28) & 8.4 & 0.46 & $126 \pm 31$ & $254 \pm 50$ & $99.1 \pm 3.9$ & $87.3 \pm 2.2$ & $102.3 \pm 0.3$ \\
\hline Steel (AISI E 52100) & 210000 (Ref. 28) & 160 & 0.3 & - & $19.0 \pm 0.7$ & $\begin{array}{c}\text { Untreated: } 57.5 \pm 0.7^{\mathrm{b}} \\
\text { plasma tr.: }<2\end{array}$ & $19.9 \pm 2.8$ & $<5$ \\
\hline Glass & 73000 (Ref. 28) & 160 & 0.17 & $2.9 \pm 0.3$ & - & $\begin{array}{c}\text { Untreated: } 32.9 \pm 3.3 \\
\text { plasma tr.: }<2\end{array}$ & $12.9 \pm 0.7$ & $<5$ \\
\hline
\end{tabular}

a6.9 MPa represents the effective Young's modulus of a $2 \mathrm{~mm}$ PDMS layer on PTFE.

${ }^{\mathrm{b}}$ Contact angle of water on 304 steel plate.

${ }^{\mathrm{c} C}$ Contact pressures in MTM experiments for PDMS-PDMS, HDPE-HDPE, and steel-glass contacts.

\section{E. Surface tension of T. baccata mucilage and wettability of tribopairs}

Pendant drop measurement of yew mucilage's surface tension was performed on a DataPhysics Contact Angle OCA instrument running software v. 4.5.8. Drop volume of $5 \mu \mathrm{l}$ was applied and three measurements were performed to obtain a mean and standard deviation. Wettability of the tribopair surfaces with $T$. baccata mucilage or water was characterized with a ramé-hart goniometer model 200-F1 running with a software version 2.4.11. Five $\mu \mathrm{l}$ of the mucilage or water were applied to the material surface and static contact angles were measured after 30 s. 304 stainless steel, glass surfaces, and oxPDMS surfaces were plasma-treated as described in Sec. II D. 304 stainless steel plate was used as a model for AISI E 52100 steel to conduct contact angle measurements.

\section{F. Minitraction machine}

A minitraction machine (MTM) (MTM2, PCS Instruments, London, UK) with software version 3.2.3.0 was employed to investigate the lubricating properties of $T$. baccata mucilage. The principal setup of MTM consists of independently rotating ball and disk under loaded contact between them. Friction forces were measured with a strain gauge connected to the ball shaft arm. Coefficient of friction ( $\mu$ ) was defined from the relationship, $\mu=F_{\text {friction }} / F_{\text {load }}$. Independent control of disk and ball speeds allows for the variation of the degree of slide/roll ratio (SRR). The mean speed was defined as $\left|\operatorname{speed}_{\text {ball }}+\operatorname{speed}_{\text {disk }}\right| / 2$. The SRR was defined as $\mathrm{SRR}=\left(\left|\operatorname{speed}_{\text {ball }}-\operatorname{speed}_{\text {disk }}\right|\right) /\left[\left(\operatorname{speed}_{\text {ball }}\right.\right.$ $\left.\left.+\operatorname{speed}_{\text {disk }}\right) / 2\right] \times 100 \%$, where $0 \%$ SRR represents pure rolling and $200 \%$ SRR represents pure sliding. The data points in Figs. 8-10 are average values of three consecutive measurements, from mean speed 5 to $1200 \mathrm{~mm} / \mathrm{s}$, unless otherwise mentioned. Error bars represent the standard deviation. The applied load was $2 \mathrm{~N}$ for hard contacts (HDPE-HDPE and steel-glass) and $5 \mathrm{~N}$ for soft contact (PDMS-PDMS), respectively. Apparent contact pressures for each tribopair were calculated according to Hertzian contact mechanics model for sphere on plane and are shown in Table I. Mucilage sample of $2 \mathrm{ml}$ was placed on the disk prior to the measurement. In case of water, tribopairs were fully submerged in the fluid. For a reference study with glycerol, both experiments with full submersion and limited supply of lubricant $(2 \mathrm{ml})$ were performed as comparison. All MTM measurements were performed at room temperature $\left(20-25^{\circ} \mathrm{C}\right)$.

\section{RESULTS AND DISCUSSION}

\section{A. Water, protein, and sugar analysis of $T$. baccata mucilage}

An overnight drying of $T$. baccata mucilage at $70^{\circ} \mathrm{C}$ showed a decrease of $81 \%$ in weight. This reduction is due to the loss of water from the yew mucilage and is comparable to a previous report. ${ }^{21}$ Figure 2 shows the crude mucilage analyzed on a 4\%-12\% SDS-PAGE. A mixture of proteins with varying molecular weights was identified with the strongest band at $\sim 40 \mathrm{kDa}$ [Fig. 2(a), second lane from left]. The mucilage also showed a significant amount of carbohydrate contents as observed on the 4\%-12\% SDS-PAGE stained with PAS [Fig. 2(b), second lane from left]. According to a previous study, ${ }^{21}$ carbohydrates represent more than $90 \%$ of the mass of solid components of T. baccata berries. More intense study is required to analyze and characterize the nature of protein and carbohydrates present in the mucilage.

\section{B. Rheological properties}

\section{Oscillation}

Oscillatory measurements are a powerful method to characterize the solid-like (elastic) and liquid-like (viscous) response of hydrogels to imposed deformation. ${ }^{30}$ The frequency $(\omega)$ dependence of elastic modulus $\left(G^{\prime}\right)$, loss modulus $\left(G^{\prime \prime}\right)$, and complex viscosity $\left(\eta^{*}\right)$ for $T$. baccata mucilage are presented in Fig. 3(a).

Within the frequency range of $0.01-20 \mathrm{rad} / \mathrm{s}$, the solidlike response $\left(G^{\prime}\right)$, is dominant over the viscous-flow $\left(G^{\prime \prime}\right)$, with little frequency dependence for both moduli [Fig. 3(a)]. It is to note that, at low frequencies (up to $0.3 \mathrm{rad} / \mathrm{s}$ ), both 
(a)

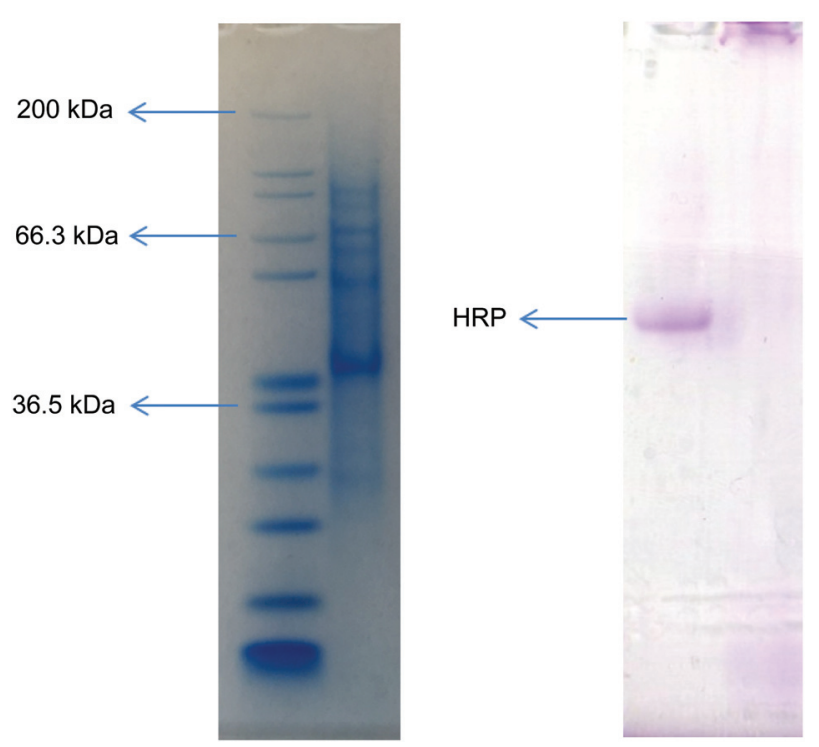

FIG. 2. SDS-PAGE gel of $4 \%-12 \%$ showing sample from $T$. baccata. (a) First lane from left indicates protein marker standard and followed by $T$. baccata whole sample stained by Simply Blue ${ }^{\mathrm{TM}}$ Safe Stain, showing the presence of protein in different molecular weight. (b) First lane from left represents standard marker as horse radish peroxidase (HRP) and followed by $T$. baccata whole sample stained by PAS (Ref. 29) showing the presence of sugar components from its stain on the top of the gel.

viscoelastic moduli were nearly independent of the frequency, as would be expected for weak gels. ${ }^{31}$ Moreover, the $\tan \delta$ value $\left(\tan \delta=G^{\prime \prime} / G^{\prime}\right)$ provides a convenient index of the proportion of liquid-like character. ${ }^{31}$ The $\tan \delta$ value is $\sim 0.24$ (at frequency $\sim 1 \mathrm{rad} / \mathrm{s}$ ) while it varies from about 0.02 to 0.07 for typical hydrocolloid gels, such as gelatin, agarose, and carrageenan. ${ }^{32,33}$ The complex viscosity versus frequency of oscillation in Fig. 3(a) has a gradient of about -0.915 , close to the limiting value of -1 in double logarithmic plots. Overall, oscillatory rheological studies indicate that $T$. baccata mucilage forms hydrogels with weak gel-like properties at room temperature.

The response to increasing shear stress for $T$. baccata mucilage is shown in Fig. 3(b). $G^{\prime}$ and $G^{\prime \prime}$ remained nearly independent of deformation at imposed strains up to $\sim 0.5 \mathrm{~Pa}$; yet, the samples effectively started to flow from $\sim 1.5 \mathrm{~Pa}$ stress with a reversal of the relative magnitude

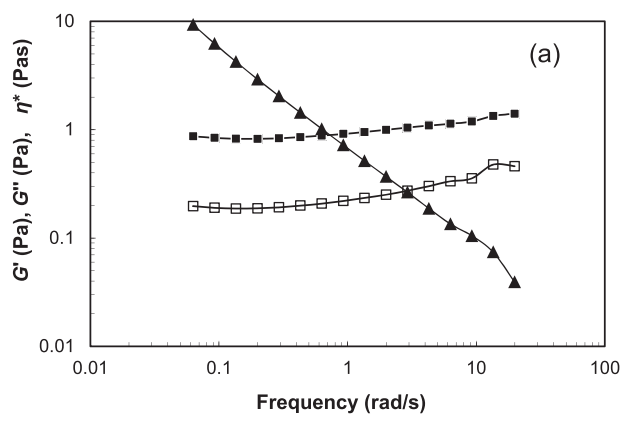

between elastic and loss moduli, i.e., $G^{\prime \prime}>G^{\prime}$. We propose that at shear stress $>1.5 \mathrm{~Pa}$, the loose entanglements and aggregates of this colloidal system were highly sheared down, and both moduli were thus substantially reduced. It is to note that strain sensitivity of the $G^{\prime}$ is higher than $G^{\prime \prime}$. This dependence of the shear moduli on oscillatory stress is another characteristic of a weak and "stretchable" macromolecular structure.

\section{Flow}

As shown in Fig. 4, flow rheological studies reveal that $T$. baccata mucilage has a shear thinning behavior (reduction in apparent viscosity with increasing shear rate), which is observed from many viscoelastic fluids and aqueous polysaccharide solutions. ${ }^{34,35}$ The hysteresis of the viscosity observed during increasing and decreasing of the imposed shear rate, i.e., thixotropy, is also shown in Fig. 4. This could be due to the destruction of the weak viscoelastic network under the action of the imposed shear and the delayed recovery in the reverse process.

The fluid follows a power-law behavior with calculated index values of $n=0.1$ and 0.3 , for increasing and decreasing shear rate, respectively, from the relationship $\eta=m \times \dot{\gamma}^{n-1}$, where $\eta$ is the apparent viscosity, $\dot{\gamma}$ is the shear rate, and $m$ is the flow index. Power law index values (n) in the range of $0.15-0.25$, implying high shear thinning behavior, have been also reported for high concentrations of polysaccharide solutions. ${ }^{36}$ This behavior is also close to that of xanthan gum $(n=0.24)$, which is known to be caused by forming aggregates through hydrogen bonds and polymer entanglements, resulting in a high viscosity at low shear rates. ${ }^{37,38}$ Aqueous preparations of xanthan are thixotropic too. $^{36}$

The first normal stress difference $(N 1)$ as a function of shear rate is illustrated in Fig. 5(a). As the shear rate was increased, the elastic forces also increased due to the stretching of polymer chains within the flow field and this resulted in increased $N 1$ values. The $N 1$ values of $T$. baccata mucilage were highly dependent on the shear rate and exhibited a power-law dependence $\left(N 1=k \times \dot{\gamma}^{(n)}\right) \quad(n=0.58)$. Comparatively, $N 1$ values of xanthan gum were less dependent on shear rate $(n=0.09) .{ }^{39}$ The ratio between $N 1$ and shear stress, which is defined as Weissenberg number (We),

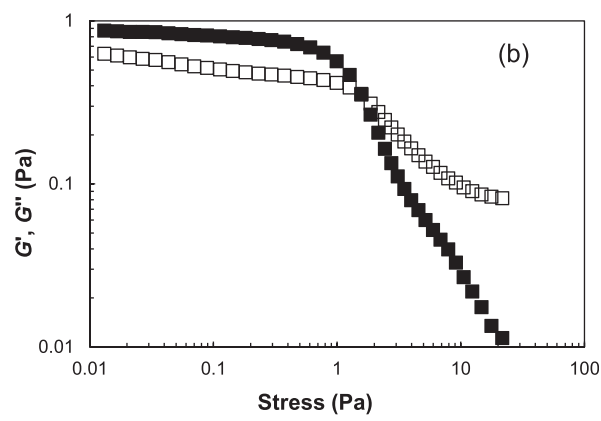

FIG. 3. Viscoelastic behavior of T. baccata mucilage as a function of (a) oscillation frequency and (b) applied shear stress (frequency at $6.2 \mathrm{rad} / \mathrm{s}$ ). Elastic modulus $G^{\prime}(\square)$, viscous modulus $G^{\prime \prime}(\square)$, and complex viscosity $\eta^{*}(\mathbf{\Lambda})$. Lines connecting the points are a guide to the eye. 


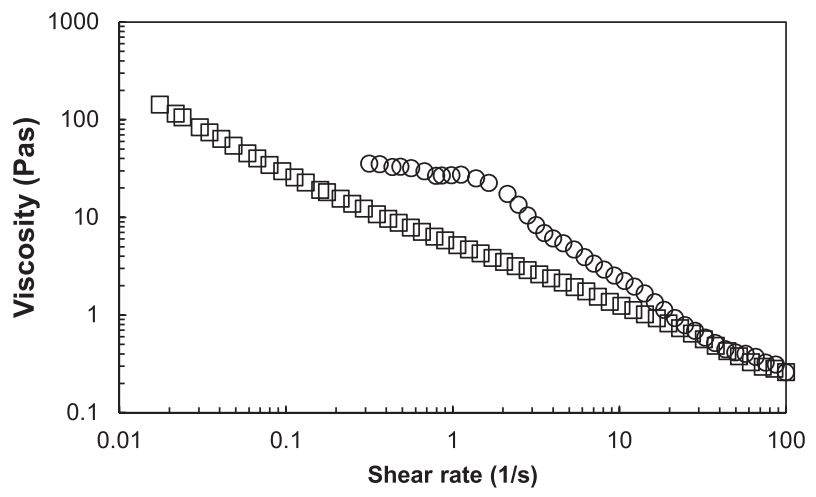

FIG. 4. Shear viscosity as a function of increasing $(\bigcirc)$ and decreasing ( $\square$ ) shear rate for T. baccata mucilage.

provides an indication on the degree of elasticity in the viscoelastic solution [Fig. 5(b)]. The data above clearly indicate that $T$. baccata mucilage is very elastic based on strong entanglements among the molecular chains, resulting in a noticeable increase of $N 1$, first normal stress difference, at high shear rates.

Figure 6 shows that the complex viscosity values of $T$. baccata mucilage are lower than the apparent viscosity values. This means that $T$. baccata mucilage does not obey the "Cox-Merz" rule which typically applies to most viscoelastic systems with physical entanglements and relates linear and nonlinear viscoelastic properties. For a majority of polysaccharide solutions, the complex viscosity is almost always higher than the apparent viscosity when the same numerical values of frequency and shear rate are compared, and their difference becomes increasingly large with decreasing frequencies and shear rates. ${ }^{30} \mathrm{~A}$ deviation from the Cox-Merz rule is generally attributed to the structural decay due to strain deformation applied to the system (i.e., low in oscillatory shear and high in steady shear). ${ }^{40}$ In the case of $T$. baccata mucilage, the complex viscosity values were lower than the apparent viscosity values at equivalent rates of deformation, as shown in Fig. 6. Similar behavior has been observed earlier in other polysaccharide systems as well, such as starch dispersions, which undergo aggregation due to their heterogeneous nature, ${ }^{40}$ high-methoxyl pectin dispersions due to its two-phase system of pectin microaggregates dispersed in a solvent, ${ }^{41}$ semidilute solution of xanthan gum in $0.5 \% \mathrm{NaCl}^{42}$ and aqueous solutions of

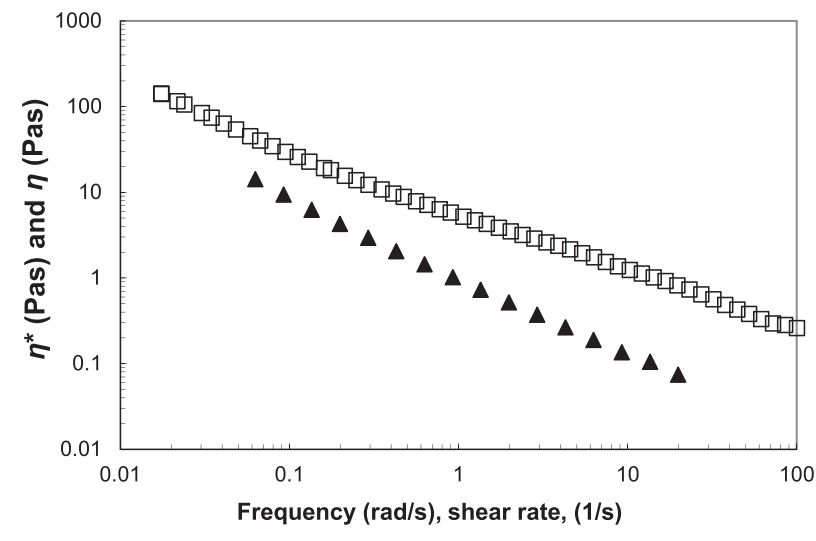

FIG. 6. Complex viscosity ( $\mathbf{\Delta}$ ) and apparent viscosity $(\square)$ as a function of frequency of oscillation and shear rate for the mucilage viscoelastic solutions.

hydroxyethyl guar gum. ${ }^{43}$ We can therefore speculate that the structural features of either hyperentanglements (i.e., high density entanglements) and/or aggregates tend to retard the decrease of apparent viscosity with increasing shear rate and it could be a possible reason for the $T$. baccata mucilage to deviate from the Cox-Merz rule.

\section{Wetting properties of mucilage to tribopair surfaces}

As will be discussed in Sec. IIID, T. baccata mucilage shows very different lubricating properties on different tribological interfaces, and the wettability on the surfaces of different tribopairs is one of the key parameters to determine the lubricity. In order to characterize the wettability of $T$. baccata mucilage on tribopair substrates, its surface tension was first measured by pendant drop method. The measured surface tension of $T$. baccata mucilage, $54.7 \pm 3.9 \mathrm{~mJ} / \mathrm{m}^{2}$, was comparatively lower than that of water $\left(72 \mathrm{~mJ} / \mathrm{m}^{2}\right),{ }^{44}$ which was ascribed to organic substances (ca. $20 \%$ in weight) present in the mucilage. The inhomogeneity and varying amount of organic substances may explain relatively large standard deviation for surface tension as well. Figure 7 shows the wetting behavior of $T$. baccata mucilage and water on PDMS, 304 stainless steel, glass, HDPE, and oxPDMS surfaces. Due to $T$. baccata mucilage and water's high surface tension, neither of them readily wet the hydrophobic HDPE and PDMS surfaces by showing the static contact angles of ca. $85^{\circ}-110^{\circ}$. In the case of hydrophilic steel,

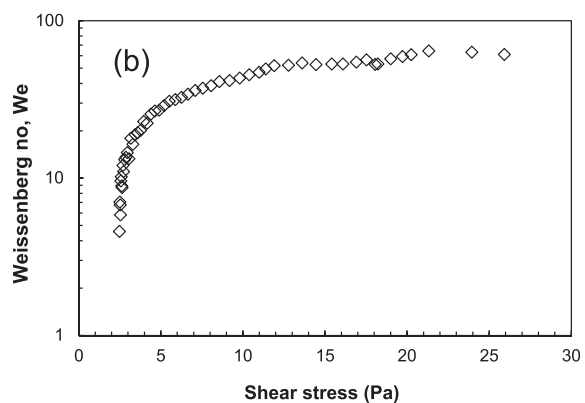

FIG. 5. (a) $N 1$ (first normal stress difference) vs shear rate and (b) Weissenberg number (We) vs shear stress for mucilage solutions (25 ${ }^{\circ} \mathrm{C}$ ). 


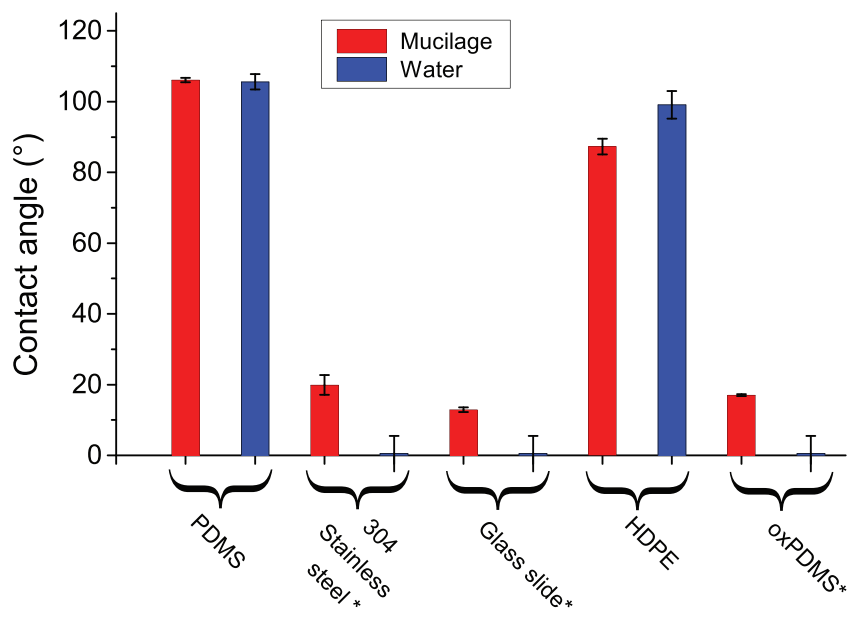

FIG. 7. Static contact angle measurement of the two fluids on tribopair material surface. *Plasma treated at $30 \mathrm{~W}$ for $2 \mathrm{~min}$.

glass, and oxPDMS surfaces, both $T$. baccata mucilage and water wetted the surfaces very well, due to high surface tension of the solid surfaces. Finally, generally better wettability (lower contact angles) by water, despite its higher surface

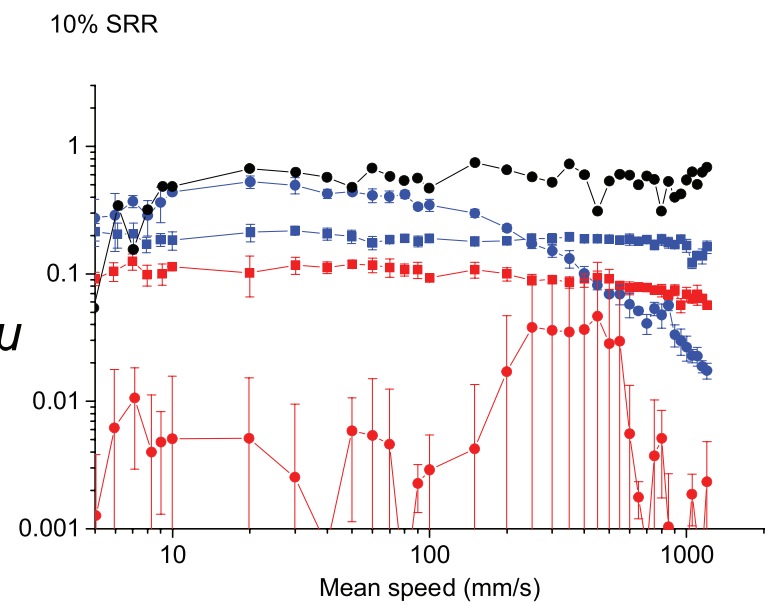

$100 \%$ SRR

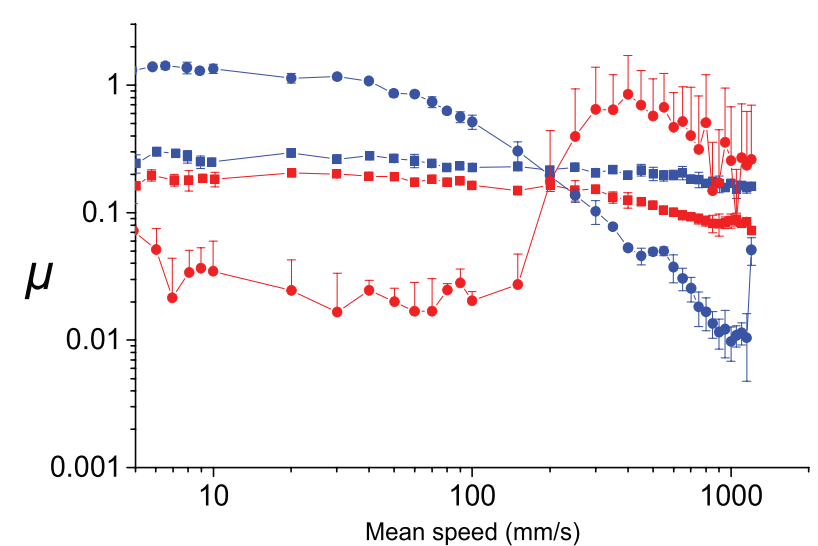

tension than $T$. baccata mucilage, on the hydrophilic surfaces was ascribed to the gel-like nature of the mucilage, hindering the spreading and wetting on surface.

\section{Lubrication: MTM friction experiments}

The $\mu$ versus mean speed plots obtained from nonwetting interfaces (HDPE-HDPE and PDMS-PDMS) and wetting interfaces (steel-glass, steel-PDMS, and oxPDMS-oxPDMS) lubricated by the mucilage are presented in Figs. 8 and 9, respectively. For each pair, SRR ratio was varied from $10 \%$ to $200 \%$. Prior to friction measurements, $2 \mathrm{ml}$ of $T$. baccata mucilage was spread along the contact track on the disk. Thus, the lubricant film thickness on the disk is ca. $1 \mathrm{~mm}$ or less, which is much smaller than the diameter of ball (19 mm). In order to assess the efficacy of lubrication by $T$. baccata mucilage, friction forces of each tribopair in dry contact should be evaluated as reference. However, the interfacial friction forces between hydrophilic surfaces in dry ambient are too high due to strong adhesion between them. Moreover, the hydrophilicity of the surface is unstable for oxidized PDMS in ambient. ${ }^{45}$ Thus, dry friction experiments

$50 \%$ SRR

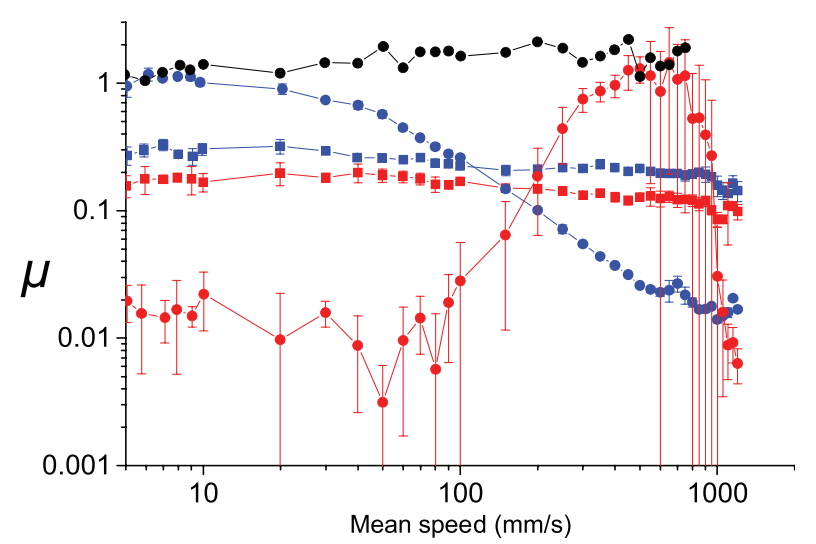

$200 \%$ SRR

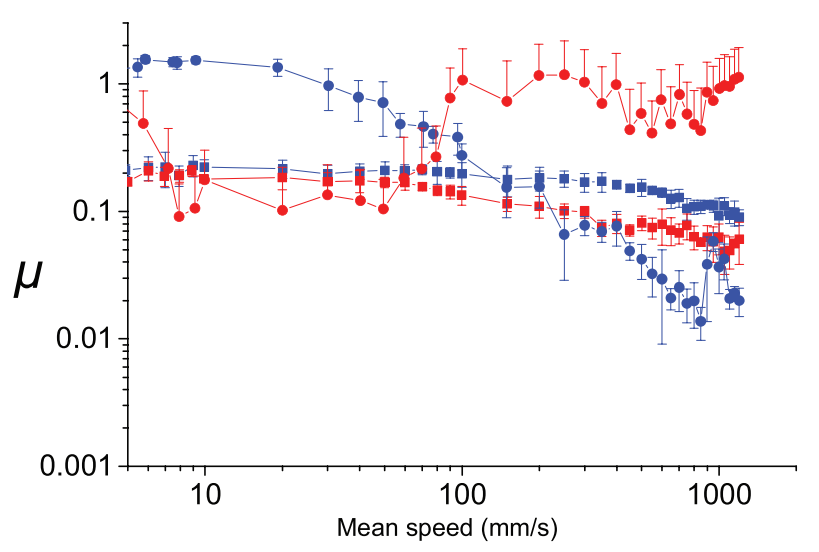

FIG. 8. $\mu$ vs mean speed plots for PDMS-PDMS (circles) and HDPE-HDPE (squares) interfaces lubricated by T. baccata mucilage (red colored symbols) or water (blue) as characterized with MTM. One run in dry contact at 10\% and 50\% SRR for PDMS-PDMS is plotted for reference (black circles). See the labels in plots for $10 \%, 50 \%, 100 \%$ and $200 \%$ SRR. For PDMS-PDMS contact lubricated with T. baccata mucilage, some negative error bars were removed for clarity. 

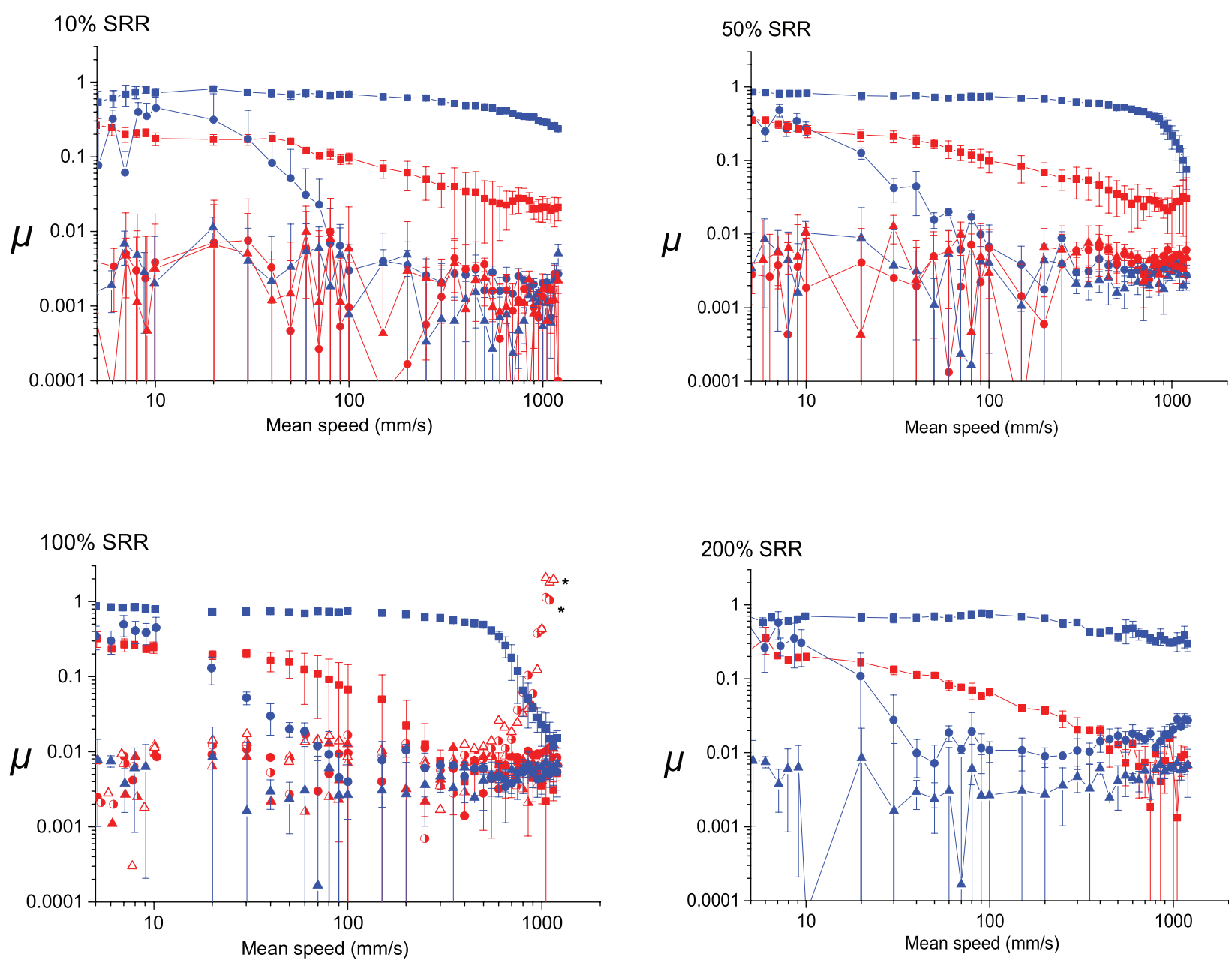

FIG. 9. $\mu$ vs mean speed plots for steel-glass, steel-PDMS, and steel-oxPDMS interfaces lubricated by T. baccata mucilage or water as characterized with MTM. Symbols for 10\%, 50\%, and 200\% SRR are steel-glass (squares), steel-PDMS (circles), steel-oxPDMS (triangles), blue symbols for water, and red symbols for mucilage. At 100\% SRR first run: filled symbols, second run: half-filled symbols and third run: empty symbols. *Measurements were discontinued because of too high friction forces in MTM instrument. Some negative error bars were removed for clarity.

as reference were carried out for the two hydrophobic interfaces only (HDPE-HDPE and PDMS-PDMS). In parallel, friction force measurements of all tribopairs fully immersed in water were taken as an alternative reference. The friction data obtained from both references are presented together with those of $T$. baccata mucilage as necessary.

\section{Nonwetting interfaces}

HDPE-HDPE pair represents nonwetting, hard interface. The tribological contacts of HDPE-HDPE lubricated by $T$. baccata mucilage showed the $\mu$ values close to 0.1 at all SRR conditions which are marginally better than those of water (Fig. 8). For all cases, the speed dependence of $\mu$ values was very weak. In fact, neither $T$. baccata mucilage nor water clearly reduced the friction forces between HDPE surfaces compared to dry tribological contacts (data shown in supplementary material, Fig. S1). ${ }^{46}$ This behavior can be first linked with poor wettability of both water and mucilage on HDPE surface (Fig. 7) and their easy depletion from the tribological interface. But as both fluids display much enhanced lubrication at similarly nonwetting, yet substantially softer interface, i.e., PDMS-PDMS (Fig. 8), high apparent contact pressure and high local contact pressure arising from the surface roughness of HDPE are also responsible for the poor lubricity (see Table I).

PDMS-PDMS pair represents nonwetting, yet soft interface. Dry contact of PDMS-PDMS at SRR 10\% and 50\% showed $\mu$ values of ca. 0.6 and 1 , respectively, over the entire speed range (Fig. 8). Higher friction forces emerge at higher SRR values due to the higher degree of shear sliding than rolling at dry conditions. The $\mu$ values at higher SRR ratios were too high to complete the experiments. The high friction forces between PDMS surfaces are generally attributed to high adhesion between them. ${ }^{47}$ For this tribopair, water and mucilage showed significantly different lubricating behavior, despite their similar wettability on HDPE. As shown in Fig. 8, lubrication of PDMS-PDMS contact with water showed decreasing trend in $\mu$ from ca. 1 to 0.01 with increasing speed from 5 to $1000 \mathrm{~mm} / \mathrm{s}$ (except for $10 \%$ SRR, where $\mu$ values at the slowest speed are $0.3-0.5)$. It is notable that water alone can lubricate PDMS-PDMS contact to a 
certain extent, especially in the high-speed regime. This can be explained as retarded activation of soft elastohydrodynamic lubrication (EHL) mechanism, ${ }^{48,49}$ in which highly compliant tribopair allows the facile formation of lubricating films with increasing speed due to low contact pressure under external load. Because of poor wettability of PDMS surface with water, however, the activation of soft EHL mechanism is delayed until very high speed is reached. ${ }^{50}$

Meanwhile, mucilage showed more drastic and different change patterns in $\mu$ with increasing speed at varying SRR. At $\mathrm{SRR}=10 \%$, for instance, $\mu<0.01$ was sustained up to ca. $100 \mathrm{~mm} / \mathrm{s}$, then increased by an order of magnitude in the speed range of ca. $110-150 \mathrm{~mm} / \mathrm{s}$ and finally decreased again to $\mu<0.01$ at higher speeds (Fig. 8). At higher $\mathrm{SRR}=50 \%$ and $100 \%$, the $\mu$ values in the low-speed regime were ca. $0.02-0.05$, and the first increase in $\mu$ values in the medium speed range (ca. $100-150 \mathrm{~mm} / \mathrm{s}$ ) was greatest. At $\mathrm{SRR}=50 \%$, in particular, 2 orders of magnitude of increase in $\mu$ values were shown. At $\mathrm{SRR}=200 \%, \mu$ values were $0.1-0.5$ in the low-speed regime, and increased in the medium speed regime again by about 1 order of magnitude. As the SRR changed from $50 \%$ to $200 \%$, the magnitude of decrease in the second transition in $\mu$ values became smaller, and consequently, the final $\mu$ values at the highest speed were gradually higher. At $200 \%$ SRR, there was no apparent second transition in $\mu$ values even at the highest speeds.

Rapid transitions in $\mu$ values with increasing speed for the mucilage-lubricated PDMS-PDMS interface are strongly related with the special rheological properties of $T$. baccata mucilage. As the initial mucilage film formed at the interface is very thin, they can be depleted from the tribological interface with increasing speed. This is a general behavior for any fluidic or semisolid lubricants (grease) in starved lubrication, regardless of their rheological characteristics. ${ }^{51,52}$ For instance, Fig. 10 shows a reference experiment result of PDMS-PDMS contacts at SRR $=10 \%$ lubricated with glycerol, a Newtonian fluid with the viscosity of ca. $1.41 \mathrm{~Pa} \mathrm{~s},{ }^{53}$ in full-flooded versus starved lubrication regimes $(2 \mathrm{ml}$, the same volume with the mucilage throughout the study).

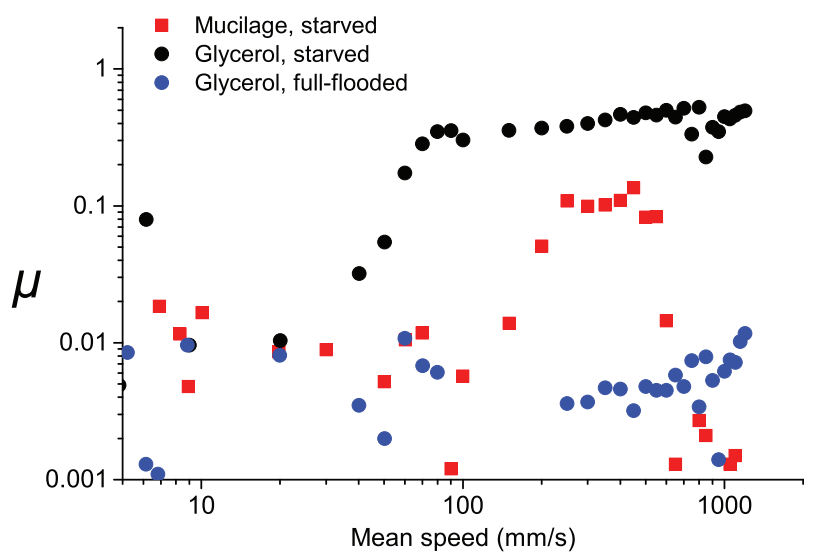

FIG. 10. Glycerol (full-flooded), glycerol (starved), and T. baccata mucilage (starved) lubrication for PDMS-PDMS contact at SRR $=10 \%$.
The full-flooded lubrication showed very low $\mu$ values of $0.002-0.004$ up to ca. $100 \mathrm{~mm} / \mathrm{s}$, followed by a slow and gradual increase in higher speed regime, a characteristic of the onset of EHL. ${ }^{54,55}$ While the starved lubrication also showed comparable low $\mu$ values in the low-speed regime, a drastic surge in $\mu$ occurred from ca. $50 \mathrm{~mm} / \mathrm{s}$. This behavior was observed at higher SRRs too (data not shown) and similar to the first transitions observed from the mucilage lubrication (Fig. 8). A clear difference between glycerol and the mucilage is that glycerol never showed the second transition of decreasing $\mu$ to lower values in even higher speed regime. This is because glycerol depletes outwards from the disk due to the dominance of centrifugal forces with increasing speed, and the lubricant cannot be replenished at even higher speeds. In contrast, the mucilage starves toward the center of the disk due to the Weissenberg effect. With a further increase in mean speed, the mucilage starts to migrate outwards from the center as the centrifugal force starts to overwhelm the Weissenberg effect, and thus, the lubricating effect at the tribological contacts can be restored (see video material in supplementary material) for the accumulation of the mucilage toward the center of the disk at an intermediate speed, and subsequent spread outwards upon stopped rotation).

\section{Wetting interfaces}

Steel-oxPDMS interface represents wetting and soft tribological interfaces, and thus differentiates from PDMS-PDMS in surface hydrophilicity or wettability by the mucilage. Even though steel was employed as counter surface, high compliance of oxPDMS disk allows for the formation of soft tribological contact (see Table I). Experiments with oxPDMS surface, especially as ball, were technically challenged because of instability of silica layer formed on PDMS surface by plasma treatment and rapid recovery of hydrophobicity in ambient. ${ }^{45}$ Steel-PDMS interface is thus employed as more stable interface, but it is half-hydrophilic in terms of wettability by water and the mucilage. Steel-PDMS and steel-oxPDMS interfaces as lubricated by the mucilage showed $\mu$ values of ca. 0.01 or lower at $10 \%$ and $50 \%$ SRR conditions over the entire speed range (Fig. 9). More enhanced and stable lubricating efficacy of the mucilage at steel-PDMS or steel-oxPDMS compared to PDMS-PDMS interface at low SRR conditions is apparently attributed to the higher wettability of the mucilage to the hydrophilic (or half-hydrophilic) interfaces. Disappearance of the abrupt increase or subsequent decrease in $\mu$ values with increasing speed implies that even Weissenberg effect of $T$. baccata mucilage could be suppressed due to highly wetting characteristics of the mucilage at these tribological interfaces. It is particularly notable that at $10 \%$ and $50 \%$ SRR, thin films of $T$. baccata mucilage (achieved from spreading of ca. $2 \mathrm{ml}$ of the fluid on the disk) revealed the equally effective lubricating performance with fully flooding water for steel-PDMS and steel-oxPDMS interfaces over the entire speed regime. For thin film lubrication under 
rotating configuration, hindered supply of the lubricants to the contact zone is a general problem, and thus, this observation highlights the significance of wettability of the mucilage on the tribopair surface to manifest its effective lubricating properties. The two interfaces started to show noticeable difference at $100 \%$ SRR condition (Fig. 9). In the case of steel-oxPDMS interface, $\mu$ values of ca. 0.01 were again maintained until the third repeat is finished (at the highest speed) where an abrupt surge of $\mu$ values were finally observed. Meanwhile, at the steel-PDMS interface, an abrupt increase in $\mu$ values was observed already in the second measurement. The different lubricating behavior of $T$. baccata mucilage at $100 \%$ SRR for steel-PDMS and steel-oxPDMS interfaces can be readily ascribed to different hydrophilicity of PDMS and oxPDMS and it further confirms the significance of surface wettability for effective lubrication by the mucilage. At $200 \%$ SRR, both soft, hydrophilic tribopairs revealed too high $\mu$ values as lubricated with $T$. baccata mucilage to conduct the experiments. Increased sliding characteristics at higher SRR ratios also mean increased shearing (and shear rates) at the interface due to the increased Couette flow. Higher shear rates then induce larger extent of shear thinning of the mucilage (as observed in Secs. III B 1 and III B 2), thus rendering effective viscosities too low to afford film thicknesses large enough to separate the tribopairs by lubricant entrainment.

Finally, the steel-glass contact represents hard and hydrophilic interface. This pair reveals similar or even superior wettability by the mucilage on steel-oxPDMS interface, but the contact pressure is much higher due to the substantially higher elasticity modulus of glass compared to oxPDMS (Table I). The $\mu$ values of the steel-glass pair lubricated by the mucilage were high (ca. 0.4-0.1) and comparable to those from HDPE-HDPE up to ca. $100 \mathrm{~mm} / \mathrm{s}$ at all SRR conditions (Fig. 8). The $\mu$ values of water-lubricated contacts were twice as high. Thus, it appears that bulk mechanical properties of the tribopair dominate the lubricating properties at low to medium speeds. But, with even further increase in speed, the $\mu$ values started to decrease significantly and reached ca. 0.01 as lubricated with the mucilage at $\mathrm{SRR} \geq 100 \%$. While this effect is also observed from the lubrication with water, ${ }^{56}$ the reduction in $\mu$ values in high-speed regime by the lubrication with the mucilage is an order of magnitude larger. Considering that the contact pressure of steel-glass interface is even higher than that of HDPE-HDPE interface (Table I), relatively more feasible lubrication of hydrophilic steel-glass pair than hydrophobic HDPE-HDPE pair by the mucilage can be attributed to its superior wettability.

\section{Lubrication mechanisms of mucilage}

A general trend in the lubricating properties of $T$. baccata mucilage as thin film lubricant is that its lubricity is effective at low contact pressure, at wetting interfaces, and low slide/ roll ratio. Wettability of lubricants has been perceived as an important parameter for many different modes of lubrication. For instance, "no slip" of lubricant fluid at the two shearing solid surfaces is a basic boundary condition that allows for velocity gradient and formulation of Reynold's hydrodynamic lubrication theory. ${ }^{57}$ Practically, this condition means perfect wetting of the solid surfaces by fluid lubricants. Alternatively, superior lubricity by nonwetting liquids based on opposing meniscus against external pressure ${ }^{58}$ or minimized Couette friction (viscous drag flow) was also suggested in previous study. ${ }^{59,60}$ The role of surface wettability of mucilage in this study is largely in the same context, but is different from those in that it does not necessarily lead to the formation of thick, fluid-film lubricants for its effective lubricity. Based on the estimation of the relative magnitude of surface roughness and the lubricating film thickness, namely, Stribeck ratio or Lambda ratio $\lambda=h_{\min } /\left(\sigma_{1}{ }^{2}+\sigma_{2}{ }^{2}\right)^{1 / 2}$ ( $h_{\text {min }}=$ minimum film thickness, $\sigma_{1}, \sigma_{2}=$ surface roughness of the two shearing surfaces) being only 0.36 even at $100 \mathrm{~mm} / \mathrm{s}^{12}$ Liu and coworkers have concluded that the extremely low coefficient of friction (0.004-0.006) between sliding quartz glasses lubricated with $B$. schreberi mucilage was achieved in boundary lubrication condition (under $10 \mathrm{~N}$, $55 \mathrm{MPa}$ ). It was further suggested that excellent boundary lubricating performance of $B$. schreberi mucilage under harsh conditions was enabled by tenacious anchoring of the mucilage on the shearing surfaces via common hydrophilic characteristics and formation of slip plane within the hydrogel network. The strong contrast in the lubricating behavior of $T$. baccata mucilage at PDMS-PDMS versus steel-oxPDMS interfaces as well as at HDPE-HDPE versus steel-glass interfaces in this study (Figs. 8 and 9) support the importance of wetting and anchoring of mucilage on the tribopair surfaces for effective lubrication.

It is important to note that the formation of slip plane within the hydrogel network implies that the network structure of hydrogel at the slip plane is disrupted and the hydrogel becomes highly stretched. In the present study, this was verified from a drastic structural change of $T$. baccata mucilage from entangled hydrogel to stretched fluid upon increasing oscillatory shear stress with a threshold of ca. $1.5 \mathrm{~Pa}$ [Fig. 2(b)]. At tribological contacts, the shear stress is even higher due to the decreased film thickness. For instance, at PDMS-PDMS contact, the friction forces can be equated to the shear force, $F_{\text {shear }}$, arising from the lubricant at the interface. Thus, the shear stress can be estimated from the following equation, $\tau=F_{\text {shear }} / A=\mu \times w / A$ where $A$ is the area of contact, $w$ is the applied load, $5 \mathrm{~N}$. This gives the shear stress, $0.001 \times 5 \mathrm{~N} / 2.1 \times 10^{-5} \mathrm{~m}^{2}=238.1 \mathrm{~Pa}$. Thus, the shear stress applied to the mucilage under tribological contacts between PDMS-PDMS is orders of magnitude higher than the threshold, ca. 1.5 Pa, of converting entangled hydrogel to highly stretched fluid of T. baccata mucilage. In other words, the unique capability of $T$. baccata mucilage that can convert from entangled hydrogel network to fluid in its structure under shear is another important contributing factor to its effective boundary lubricating properties. Nevertheless, the mucilage can recover gel-like network structure upon release of tribostress, as the formation of crosslinked structure is achieved mainly via physical interactions. 


\section{SUMMARY AND CONCLUSIONS}

In this study, we have investigated the rheological and lubricating properties of mucilage from arils of $T$. baccata as inspired from recent slippery characteristics reported on a variety of plant mucilage. These properties were investigated by employing various tribopairs with different bulk elasticity and surface wettability, and at varying slide/roll ratio over a wide speed range. The viscoelastic properties of $T$. baccata mucilage studied by oscillation showed a typical weak gellike physical network and a highly stretchable (elastic) structure. Flow rheological studies with increasing shear rate showed distinctive shear thinning and thixotropic properties. The most notable rheological features observed are: (1) its increasing first normal stress difference with increasing shear rate, namely, Weissenberg effect, which significantly influenced its lubricating properties as well, and (2) the deviation from the Cox-Merz rule due to presence of high density physical entanglements. Systematic variation of bulk mechanical properties and surface wettability of the tribopairs has shown that the mucilage's lubricity is best manifested at a hydrophilic (wetting) and soft interface, for example, steel-oxPDMS, at low slide/roll ratio. Even the Weissenberg effect of T. baccata mucilage, which contributed to depletion of the lubricant from soft hydrophobic interface (PDMS-PDMS), is effectively suppressed provided that the mucilage can wet the surface, as observed in steel-oxPDMS or steel-glass interfaces. Tenacious bonding of mucilage on the hydrophilic surfaces is thought to formulate the basis for excellent boundary lubricating properties. It is also proposed that conversion of the mucilage from entangled gel-like structure to fluidlike one under high shear stress further contributes to its excellent lubricating properties. The outstanding lubricating properties exhibited by $T$. baccata mucilage particularly at soft hydrophilic interface (including halfhydrophilic interface) suggests that it has a high potential as fluid lubricant for biomedical applications such as endoscopes, catheters, or as personal lubricants, where the contact characteristic is basically soft and hydrophilic. ${ }^{56,57}$ Further in vitro lubrication studies of $T$. baccata mucilage as well as biocompatibility studies would be necessary to facilitate the application of mucilage as a hydrogel fluid lubricant for biomedical devices.

\section{ACKNOWLEDGMENTS}

The authors thank European Research Council (Funding scheme: ERC Starting Grant 2010, Project No. 261152) for its financial support. The authors also thank Heidi Olander Petersen and Peter Reimer Stubbe (DTU-Food) for their assistance with the rheological experiments.

${ }^{1}$ X. J. Yang, J. M. Baskin, C. C. Baskin, and Z. Y. Huang, Perspect. Plant Ecol. Evol. Syst. 14, 434 (2012).

${ }^{2}$ T. L. Western, Seed Sci. Res. 22, 1 (2012).

${ }^{3}$ Y. J. Huang, Y. Z. Wang, L. M. Sun, R. Agrawal, and M. J. Zhang, J. R. Soc., Interface 12, 20150226 (2015).

${ }^{4}$ P. Erni, M. Varagnat, C. Clasen, J. Crest, and G. H. McKinley, Soft Matter 7, 10889 (2011).
${ }^{5}$ G. T. Kulkarni, K. Gowthamarajan, G. B. Rao, and B. Suresh, J. Sci. Ind. Res. 61, 529 (2002).

${ }^{6}$ R. Kumar, S. Patil, M. B. Patil, S. R. Patil, and M. S. Paschapur, Int. J. PharmTech. Res. 1, 982 (2009).

${ }^{7}$ M. Parihar, A. Chouhan, M. S. Harsoliya, J. K. Pathan, S. Banerjee, N. Kahn, and V. M. Patel, Int. J. Nat. Prod. Res. 1, 9 (2011).

8“"Curry's artists' materials," https://www.currys.com/.

${ }^{9}$ J. Xu, J. B. Luo, S. H. Liu, G. X. Xie, and L. Ma, Tribol.-Mater. Surf. Interfaces 2, 72 (2008).

${ }^{10}$ T. J. Hakala, V. Saikko, S. Arola, T. Ahlroos, A. Helle, P. Kuosmanen, K. Holmberg, M. B. Linder, and P. Laaksonen, Tribol. Int. 77, 24 (2014).

${ }^{11}$ J. J. Li, Y. H. Liu, J. B. Luo, P. X. Liu, and C. H. Zhang, Langmuir 28, 7797 (2012).

${ }^{12}$ P. X. Liu, Y. H. Liu, Y. Yang, Z. Chen, J. J. Li, and J. B. Luo, Langmuir 30, 3811 (2014).

${ }^{13}$ M. Brown, J. D. Fotheringham, T. J. Hoyes, R. M. Mortier, S. T. Orszulik, S. J. Randles, and P. M. Stroud, "Synthetic base fluids," in Chemistry and Technology of Lubricants (Springer, London, 2010).

${ }^{14}$ S. Sasaki, J. Mech. Sci. Technol. 24, 67 (2010).

${ }^{15}$ A. Koocheki, S. A. Mortazavi, F. Shahidi, S. M. A. Razavi, and A. R. Taherian, J. Food Eng. 91, 490 (2009).

${ }^{16}$ W. N. Deng, P. P. M. Iannetta, P. D. Hallett, P. E. Toorop, G. R. Squire, and D. S. Jeng, Biorheology 50, 57 (2013).

${ }^{17}$ A. Harnoy, "Lubricant viscosity," in Bearing Design in Machinery: Engineering Tribology and Lubrication (Marcel Dekker, New York, 2003).

${ }^{18}$ A. F. M. Willich, The Domestic Encyclopaedia or a Dictionary of Facts, and Useful Knowledge (William Young Birch, Philadelphia, 1804).

${ }^{19}$ A. F. Skutch, Condor 82, 31 (1980).

${ }^{20}$ C. M. Herrera, Ecol. Monogr. 57, 305 (1987).

${ }^{21}$ P. A. Thomas and A. Polwart, J. Ecol. 91, 489 (2003).

${ }^{22}$ A. Barnea, J. B. Harborne, and C. Pannell, Biochem. Syst. Ecol. 21, 421 (1993).

${ }^{23}$ P. Gasson, J. Lees, and G. Kite, Mammal Notes 1, 1 (2009).

${ }^{24} \mathrm{~K}$. Weissenberg, Nature 159, 310 (1947).

${ }^{25}$ T. Røn, I. Javakhishvili, K. Jankova, S. Hvilsted, and S. Lee, Langmuir 29, 7782 (2013).

${ }^{26}$ J. E. Mark, Polymer Data Handbook (Oxford University, New York, 1999).

${ }^{27}$ The effective Young's modulus of composite layers in the antiparallel direction of the layers is calculated fro the relation: $E=(f 1 / E 1+f 2 / E 2)-$ 1, where $\mathrm{fx}$ is volume fraction the material and Ex is the bulk Young's modulus. For the case of $2 \mathrm{~mm}$ PDMS layer on a $5 \mathrm{~mm}$ thick PTFE disk the effective young's modulus is: $((0.2 / 0.7) / 2 \mathrm{MPa}+(0.5 / 0.7) / 550 \mathrm{MPa}))$ $-1=6.9 \mathrm{MPa}$.

28،"MatWeb, material property data,"www.matweb.com.

${ }^{29}$ R. M. Zacharius, T. E. Zell, J. H. Morrison, and J. J. Woodlock, Anal. Biochem. 30, 148 (1969).

${ }^{30}$ D. R. Picout and S. B. Ross-Murphy, Sci. World J. 3, 105 (2003).

${ }^{31}$ S. B. Ross-Murphy, J. Rheol. 39, 1451 (1995).

${ }^{32}$ I. S. Chronakis, L. Piculell, and J. Borgstrom, Carbohydr. Polym. 31, 215 (1996).

${ }^{33}$ I. S. Chronakis, J. L. Doublier, and L. Piculell, Int. J. Biol. Macromol. 28 , 1 (2000).

${ }^{34}$ E. R. Morris, "Polysaccharide solution properties: Origin, rheological characterization and implactions for food systems," in Frontiers in Carbohydrate Research (Elsevier, London, 1989).

${ }^{35}$ J. R. Stokes, L. Macakova, A. Chojnicka-Psazun, C. G. de Kruif, and H. H. de Jongh, Langmuir 27, 3474 (2011).

${ }^{36}$ B. Launay, J. L. Doublier, and G. Cuvelier, "Flow properties of aqueous solutions and dispersions of polysaccharides," in Functional Properties of Food Macromolecules (Elsevier Applied Science, London/New York, 1986).

${ }^{37}$ B. Wei, L. Romero-Zeron, and D. Rodrigue, J. Pet. Explor. Prod. Technol. 4, 113 (2014).

${ }^{38}$ K. W. Song, Y. S. Kim, and G. S. Chang, Fiber Polym. 7, 129 (2006).

${ }^{39}$ B. Wei, L. Romero-Zeron, and D. Rodrigue, J. Macromol. Sci. B 53, 625 (2014).

${ }^{40}$ E. K. Chamberlain and M. A. Rao, Carbohydr. Polym. 40, 251 (1999).

${ }^{41}$ J. A. L. da Silva, M. P. Goncalves, and M. A. Rao, J. Food Eng. 18, 211 (1993). 
${ }^{42}$ W. E. Rochefort and S. Middleman, J. Rheol. 31, 337 (1987).

${ }^{43}$ R. Lapasin, S. Pricl, and P. Tracanelli, Carbohydr. Polym. 14, 411 (1991).

${ }^{44}$ David R. Lide, CRC Handbook of Chemistry and Physics, 89 ed. (Taylor and Francis Group LLC, Boca Raton, FL, 2009).

${ }^{45}$ S. K. Sia and G. M. Whitesides, Electrophoresis 24, 3563 (2003).

${ }^{46}$ See supplementary material at http://dx.doi.org/10.1116/1.4942208 for video of MTM contact showing depletion of mucilage towards the center at higher rotation/mean speeds.

${ }^{47}$ M. K. Chaudhury and M. J. Owen, Langmuir 9, 29 (1993).

${ }^{48}$ B. J. Hamrock and D. Dowson, Proceedings of the 5th Leeds-Lyon Symposium on Tribology, Bury St. Edmunds, Suffolk (Mechanical Engineering, 1979), pp. 22-27.

${ }^{49}$ M. Esfahanian and B. J. Hamrock, Tribol. Trans. 34, 628 (1991).
${ }^{50}$ S. Lee and N. D. Spencer, Tribol. Int. 38, 922 (2005).

${ }^{51}$ B. J. Hamrock and D. Dowson, Trans. ASME 101, 92 (1991).

${ }^{52}$ B. Damiens, C. H. Venner, P. M. E. Cann, and A. A. Lubrecht, J. Tribol.-Trans. ASME 126, 105 (2004).

${ }^{53}$ J. B. Segur and H. E. Oberstar, Ind. Eng. Chem. 43, 2117 (1951).

${ }^{54}$ J. H. H. Bongaerts, K. Fourtouni, and J. R. Stokes, Tribol. Int. 40, 1531 (2007).

${ }^{55}$ G. Cassin, E. Heinrich, and H. A. Spikes, Tribol. Lett. 11, 95 (2001).

${ }^{56}$ T. Røn and S. Lee, Lubricants 2, 177 (2014).

${ }^{57}$ G. W. Stachowiak and A. W. Batchelor, Engineering Tribology, 3rd ed. (Elsevier Butterworth-Heinemann, Amsterdam/Boston, 2005).

${ }^{58}$ J. Chappuis, Wear 77, 303 (1982).

${ }^{59}$ H. A. Spikes, Proc. Inst. Mech. Eng., Part J 217, 1 (2003).

${ }^{60}$ H. A. Spikes, Proc. Inst. Mech. Eng., Part J 217, 15 (2003). 